\title{
Comparison of long-term oncologic outcomes of laparoscopic gastrectomy and open gastrectomy for advanced gastric cancer: A retrospective cohort study
}

\author{
Ji-Ho Park', Sang-Ho Jeong², Young-Joon Lee', Tae Han Kim², Jae-Myung Kim', Seung-Jin Kwag', Ju-Yeon Kim', Taejin Park², \\ Chi-Young Jeong', Young-Tae Ju', Eun-Jung Jung'2, Soon-Chan Hong', Woo-Song Ha ${ }^{1}$ \\ 'Department of Surgery, Gyeongsang National University Hospital, Gyeongsang National University College of Medicine, Jinju; \\ ${ }^{2}$ Department of Surgery, Gyeongsang National University Changwon Hospital, Gyeongsang National University College of Medicine, Changwon, Korea
}

Purpose: We investigated the long-term oncologic outcomes of laparoscopic gastrectomy (LG) and open gastrectomy (OG) for advanced gastric cancer (AGC) with a 5-year follow-up period.

Methods: Clinical data of 180 patients (109 LG and 71 OG) who underwent radical D2 gastrectomy for AGC at Gyeongsang National University Hospital between 2007 and 2009 were included. Survivals and predictors of these outcomes were analyzed.

Results: The mean follow-up period was 54.3 months. Recurrence was observed in 68 patients (37.8\%). The 5-year disease-free survival (DFS) rate was 52.2\% for all patients, 39.4\% in the OG group, and 60.6\% in the LG group. The 5-year DFS rates for OG and LG with respect to pathological stage were stage $I, 87.5 \%$ and $84.2 \%$, respectively $(P=0.684)$; stage $I I, 55.0 \%$ and $77.3 \%$, respectively $(P=0.032)$; and stage III, $23.3 \%$ and $34.8 \%$, respectively $(P=0.265)$. The 5 -year overall survival $(\mathrm{OS})$ rate was $52.8 \%$ for all patients, $40.8 \%$ in the $0 \mathrm{G}$ group, and $60.6 \%$ in the LG group. The 5-year OS rates for $\mathrm{OG}$ and LG with respect to pathological stage were stage I, 87.5\% and 84.2\%, respectively $(P=0.753)$; stage $I I, 55.0 \%$ and $77.3 \%$, respectively $(P=0.034)$; and stage $I I I, 25.6 \%$ and $34.8 \%$, respectively $(P=0.302)$. For survival, TMN cancer stage was statistically independent prognostic factors.

Conclusion: Our analysis revealed that LG for AGC had acceptable long-term oncologic outcomes comparable to the outcomes of conventional OG. Cancer stage was independent risk factors associated with survival.

Keywords: Laparoscopic gastrectomy, Stomach neoplasms, Advanced gastric cancer, Survival, Recurrence

\section{INTRODUCTION}

Recently, laparoscopic gastrectomy (LG) has been widely used to treat early gastric cancer (EGC). Various reports have established the short-term and long-term benefits of LG for EGC with 5-year survival rates exceeding 95\% [1-4]. In addition, several publications have described the short-term and long-term outcomes of

Received: Feb 20, 2018 Accepted: Jun 4, 2018

Correspondence to: Young-Joon Lee

Department of Surgery, Gyeongsang National University College of

Medicine, 79 Gangnam-ro, Jinju 52727, Korea

Tel: +82-55-750-8096, Fax: +82-55-757-5442

E-mail: orangejulia@naver.com

Copyright (C) Korean Society of Surgical Oncology

This is an Open Access article distributed under the terms of the Creative Commons Attribution Non-Commercial License (http://creativecommons.org/licenses/by-nc/4.0) which permits unrestricted non-commercial use, distribution, and reproduction in any medium, provided the original work is properly cited.
LG with D2 lymphadenectomy in advanced gastric cancer (AGC) as equivalent to those of open gastrectomy (OG) [5-10]. However, the indications for LG as treatment for AGC still remain controversial. There are several concerns about the technical feasibility and safety of LG for AGC and the lack of studies showing the longterm oncologic outcomes with sufficient follow-up periods.

The aim of the current study was to investigate the oncologic outcomes, including disease-free survival (DFS) rate, overall survival (OS) rate, and prognostic factors of survival, of patients undergoing LG vs. OG.

\section{METHODS}

Patients

Between January 2007 and December 2009, 398 consecutive patients underwent radical gastrectomy for gastric cancer at Gyeong- 
sang National University Hospital. We collected data for 180 patients (71 OG and 109 LG patients) who satisfied the following inclusion criteria: gastrectomy with curative intent, pathologically confirmed gastric adenocarcinoma with T2, T3, or T4 invasion, an R0 resection, and no evidence of distant metastasis. Patients with pathologic T1 invasion, other primary malignancies, or recurrent or remnant gastric cancers, were excluded from this analysis. All gastrectomy procedures were performed by an experienced surgeon (Y.J.L.) who had previously performed 50 LG surgeries (at least 30 laparoscopic D2 gastrectomies) for EGC between 2003 and 2006. We performed LG in patients diagnosed as having clinically T1N0 (defined according to the American Joint Committee on Cancer [AJCC], 6th edition) gastric cancer before January 2005 [11]. The indication for undergoing LG with D2 lymphadenectomy was then extended to include clinically T3N1 gastric cancer (AJCC, 6th edition). The decision to undergo OG or LG was decided mainly by the patients' approval after sufficient explanation of the surgical and oncologic risks of this procedure.

Patient demographics, operative data, and early surgical outcomes were reviewed. The emphasis was on long-term outcomes including the DFS rates, OS rates, and recurrence rates. Recurrence of disease was diagnosed by history, physical examination, endoscopic evaluation, radiologic investigations including chest radiography, computed tomography (CT) scan, and ultrasound, and peritoneal fluid cytology. In accordance with our management protocol, patients with stage II, IIIA, or IIIB tumors were received 5-fluorouracil based adjuvant chemotherapy. Complication were defined based on Korean laparoscopy gastrointestinal surgery study group's report on complication following gastrectomy [3].

Survival data were collected by reviewing electronic medical records and by conducting telephone interviews (January 1, 2015 to February 25, 2015). In case of death, death was confirmed and causes of death were determined by searching the micro-data services of the National Statistical Office. This study was approved by the Institutional Review Board of Gyeongsang National University Hospital (IRB No. GNUH 2014-01-013).

\section{Surgical procedures}

Most patients were treated with radical gastrectomy and D2 or more lymph node dissection according to the Japanese Classification of Gastric Carcinoma from 1998 [12]. When preoperative gastric fibroscopy and spiral CT scanning diagnosed a clinical T1 tumor, partial omentectomy and D1 $+\beta$ lymph node dissection were performed. Depending on the location and macroscopic type of the tumor, we performed a distal, total, or proximal gastrectomy.

In the past, we have reported our surgical procedures of laparoscopy-assisted distal and total gastrectomy, focused primarily on re- construction technique $[13,14]$. The LG procedure at our institution can be summarized as follows: the patient is placed in the supine position with split legs. After creation of pneumoperitoneum with carbon dioxide insufflation at a pressure of about $12 \mathrm{mmHg}$, the operation continues using the five-port technique. With regard to LG for mid- and lower-body cancer, lymph nodes in stations no. 7, 8a, 9, 11p, 12a, and 14v are dissected in addition to D1 stations. When LG is performed for upper body cancer, lymph nodes in stations no. 7, 8a, 9, 10,11p, 11d, and 12a are resected in addition to perigastric lymph nodes. Whenever we perform lymph node dissection, we routinely make it a practice to check each anatomic landmark vessel and structure. We do not routinely use combined splenectomy. However, when lymph node station no. 10 was likely to metastasize or there was a locally advanced tumor located mainly on the side of the great curvature of the upper stomach, we performed combined resection of the spleen [15].

For reconstruction with LG, extracorporeal Billroth I, Billroth II, or Roux-en-Y esophagojejunostomy and esophagogastrostomy using upper midline or right subcostal transverse minilaparotomy were performed. While an extracorporeal anastomosis was initially made during the Billroth I procedure, the stapled intracorporeal gastroduodenostomy was created using a hand-access device as described in 2007 [13]. For the Billroth II procedure, we completed the gastrojejunostomy by hand sewing through the upper midline minilaparotomy skin incision. When we conducted laparoscopy-assisted total gastrectomy, reconstruction involved an extracorporeal end-to-side Roux-en-Y esophagojejunostomy generated by the circular stapler through an upper minilaparotomy [14]. The esophagogastrostomy was performed using the gastric tube reconstruction method [16].

\section{Statistical analysis}

All continuous values are presented as the mean \pm standard deviation. A chi-square test and a Student t-test were conducted to compare nominal and continuous variables between groups, respectively. DFS was defined as the interval from the date of the operation to the date of the first recurrence or the date of the telephone interview. OS was defined as the interval from the date of operation to the date of death or the date of the telephone interview. Patients alive at the last follow-up visit were censored. DFS and OS rates were calculated using the Kaplan-Meier method and examined by the long-rank test. Multivariable Cox proportional hazards regression was used to determine independent predictors of outcome. A P-value less than 0.05 was considered statistically significant in all analyses. The IBM SPSS Statistics version 20 software (IBM Corp., Armonk, NY, USA) was used to perform the analyses. 


\section{RESULTS}

\section{Clinicopathological characteristics}

Clinicopathological characteristics, operative data, and early surgi-

Table 1. Differences in clinicopathologic characteristics of patients undergoing open or laparoscopy gastrectomy

\begin{tabular}{|c|c|c|c|}
\hline Characteristics & OG $(n=71)$ & LG $(n=109)$ & P-value \\
\hline Age (yr) & $64.0 \pm 10.1$ & $61.5 \pm 11.0$ & 0.132 \\
\hline Sex (male/female) & $45 / 26$ & $70 / 39$ & 0.784 \\
\hline BMI $\left(\mathrm{kg} / \mathrm{m}^{2}\right)$ & $21.4 \pm 3.9$ & $22.7 \pm 3.5$ & 0.684 \\
\hline Co-morbidities & $38(53.5)$ & $47(43.1)$ & 0.221 \\
\hline $\operatorname{ASA}(\geq 3)$ & $9(12.7)$ & $4(3.7)$ & 0.071 \\
\hline Tumor location & & & 0.893 \\
\hline Upper & $12(16.9)$ & $22(20.2)$ & \\
\hline Middle & $8(11.3)$ & $13(11.9)$ & \\
\hline Low & $49(69.0)$ & $72(66.1)$ & \\
\hline Diffuse & $2(2.8)$ & $2(1.8)$ & \\
\hline Tumor invasion & & & 0.256 \\
\hline $\mathrm{T} 2$ & $16(22.5)$ & $28(25.7)$ & \\
\hline T3 & $40(56.3)$ & $64(58.7)$ & \\
\hline T4 & $15(21.1)$ & $17(15.6)$ & \\
\hline Lymph node metastasis & & & 0.032 \\
\hline No & $20(28.2)$ & $48(44.0)$ & \\
\hline N1 & $9(12.7)$ & $18(16.5)$ & \\
\hline N2 & $19(26.8)$ & $15(13.5)$ & \\
\hline N3 & $23(32.4)$ & $28(25.7)$ & \\
\hline TNM stage & & & 0.028 \\
\hline । & $8(11.3)$ & $19(17.4)$ & \\
\hline$\|$ & $20(28.3)$ & $44(40.4)$ & \\
\hline III & $43(60.6)$ & $46(42.2)$ & \\
\hline Long diameter of main lesion (mm) & $62 \pm 28$ & $54 \pm 25$ & 0.046 \\
\hline Proximal resection margin $(\mathrm{mm})$ & $49 \pm 34$ & $42 \pm 28$ & 0.125 \\
\hline Distal resection margin (mm) & $40 \pm 41$ & $50 \pm 48$ & 0.159 \\
\hline No. of retrieved lymph nodes & $34.9 \pm 14.1$ & $28.5 \pm 13.9$ & 0.012 \\
\hline No. of metastatic lymph nodes & $6.4 \pm 8.6$ & $3.9 \pm 5.9$ & 0.034 \\
\hline Type of gastrectomy & & & 0.544 \\
\hline Distal & $43(60.6)$ & $67(61.5)$ & \\
\hline Total & $25(35.5)$ & 34 (31.2) & \\
\hline Proximal & $3(4.2)$ & $8(7.3)$ & \\
\hline Type of reconstruction & & & 0.110 \\
\hline Billroth I & $32(45.1)$ & $37(33.9)$ & \\
\hline Billroth II & $11(15.5)$ & $30(27.5)$ & \\
\hline Roux-en-Y esophagojejunostomy & $25(35.2)$ & $34(31.2)$ & \\
\hline Esophagogastrostomy & $3(4.2)$ & $8(7.3)$ & \\
\hline Operation time (min) & $264.3 \pm 95.1$ & $322.9 \pm 116.6$ & 0.001 \\
\hline Combined organ resection & $27(38.0)$ & $17(15.6)$ & 0.002 \\
\hline Hospital stay (day) & $18.2 \pm 12.9$ & $17.1 \pm 10.7$ & 0.434 \\
\hline Time to first flatus (day) & $4.1 \pm 1.1$ & $3.8 \pm 1.1$ & 0.287 \\
\hline Postoperative complication & $18(25.4)$ & $32(29.4)$ & 0.554 \\
\hline Adjuvant chemotherapy & $58(81.7)$ & $90(82.6)$ & 0.881 \\
\hline
\end{tabular}

Values are presented as mean \pm standard deviation or number (\%).

OG, open gastrectomy; LG, laparoscopic gastrectomy; BMI, body mass index; ASA, American Society of Anesthesiologists score; TNM, tumor node metastasis. cal outcomes of the studied patients are summarized in Table 1 . The groups were similar with respect to age, gender, body mass index, co-morbidities, and American Society of Anesthesiologists (ASA) score. No differences in pathological data were observed between groups for tumor location, tumor invasion (T status), proximal resection margin, or distal resection margin. However, the OG group had significantly advanced $\mathrm{N}$ status $(\mathrm{P}=0.032)$ and tumor node metastasis (TNM) stage ( $\mathrm{P}=0.028)$. In addition, significantly more lymph nodes (OG vs. LG: 34.9 vs. 28.5; $\mathrm{P}=0.012$ ) and metastatic lymph nodes (6.4 vs. 3.9 , respectively; $\mathrm{P}=0.034$ ) were retrieved in the OG group. In addition, the mean long diameter of the main tumor was significantly longer in the OG group (62 mm vs. $54 \mathrm{~mm}$, respectively; $\mathrm{P}=0.046$ ).

The mean operation time was significantly longer in the LG group (264.3 minutes vs. 322.9 minutes, respectively; $\mathrm{P}=0.001$ ). Combined organ resection was performed more frequently in the OG group than the LG group (38.0\% vs. $15.6 \%$, respectively; $\mathrm{P}=0.002$ ). Other operative findings, the type of gastrectomy (distal/total/proximal), and reconstruction (Billroth I/Billroth II/Roux-en-Y esophagojejunostomy/esophagogastrostomy), were comparable between the two groups. With regard to early surgical outcomes, including mean hospital stay, time to first flatus, postoperative complication rate, and adjuvant chemotherapy, no significant difference was observed between the two groups. There was no mortality in this study.

\section{Survival and recurrence analysis}

Five-year oncologic outcomes in this study are summarized in Table 2. The mean follow-up period was 54.3 months. The 5 -year DFS rate was $52.2 \%$ for all patients, $39.4 \%$ in the OG group, and $60.6 \%$ in the LG group (Fig. 1A). The 5-year DFS rates for OG and LG with respect to pathological stage were (1) stage I, $87.5 \%$ and

Table 2. Five-year oncologic outcomes for open gastrectomy and laparoscopic gastrectomy

\begin{tabular}{lcccc}
\hline Outcome & Total & $\begin{array}{c}\text { OG } \\
(n=71)\end{array}$ & $\begin{array}{c}\text { LG } \\
(n=109)\end{array}$ & P-value \\
\hline Follow-up period, mean $\pm S D$, mo & $54.3 \pm 29.5$ & $46.1 \pm 29.1$ & $59.7 \pm 28.1$ & 0.011 \\
Disease-free survival (total \%) & 52.2 & 39.4 & 60.6 & 0.008 \\
Stage I & 85.2 & 87.5 & 84.2 & 0.684 \\
Stage II & 70.3 & 55.0 & 77.3 & 0.032 \\
Stage III & 29.2 & 23.3 & 34.8 & 0.265 \\
Overall survival (total \%) & 52.8 & 40.8 & 60.6 & 0.008 \\
Stage I & 85.2 & 87.5 & 84.2 & 0.753 \\
Stage II & 70.3 & 55.0 & 77.3 & 0.034 \\
Stage III & 30.3 & 25.6 & 34.8 & 0.302 \\
Rate of recurrence (\%) & 37.8 & 50.7 & 29.4 & 0.005 \\
\hline
\end{tabular}

OG, open gastrectomy; LG, laparoscopic gastrectomy; SD, standard deviation. 

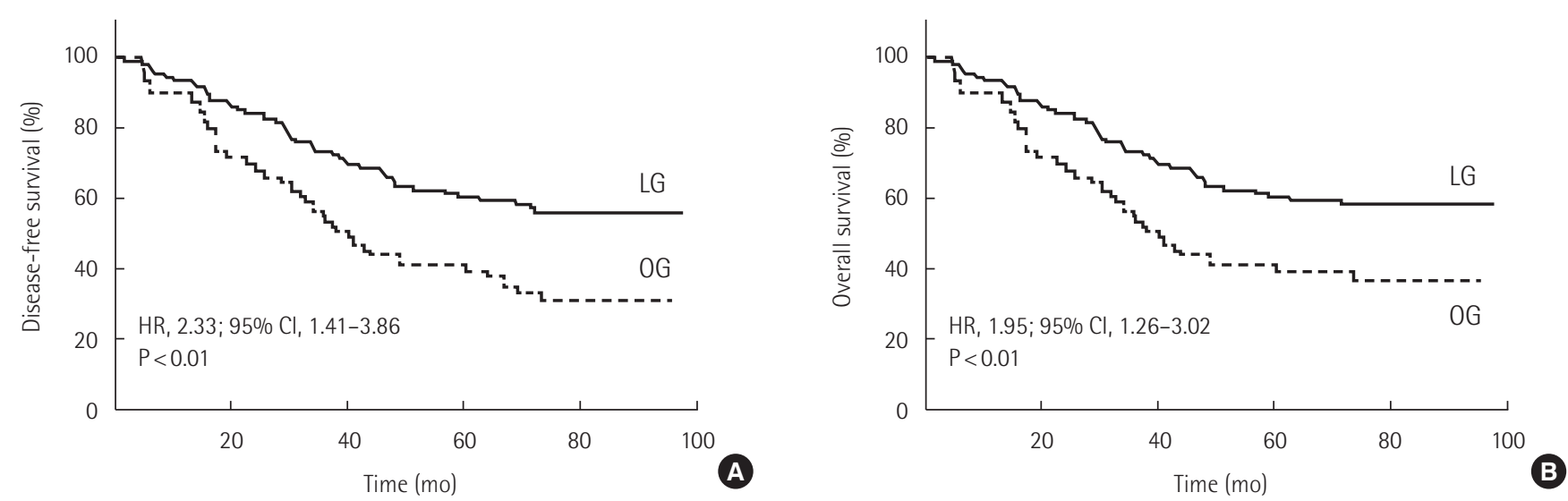

Fig. 1. Kaplan-Meier estimates of disease-free survival and overall survival. (A) Five years after surgery, the rate of disease-free survival was $60.6 \%$ in the laparoscopic gastrectomy (LG) group and $39.4 \%$ in the open gastrectomy (OG) group, and (B) the rate of overall survival was $60.6 \%$ in the $L G$ group and $40.8 \%$ in the $0 \mathrm{G}$ group. P-values were calculated with the use of the stratified log-rank test. HR, hazard ratio; $\mathrm{Cl}$, confidence interval.

84.2\%, respectively $(\mathrm{P}=0.684)$; (2) stage II, $55.0 \%$ and $77.3 \%$, respectively $(\mathrm{P}=0.032)$; and (3) stage III, $23.3 \%$ and $34.8 \%$, respectively $(\mathrm{P}=0.265)$ (Fig. 2).

The 5-year OS rate was 52.8\% for all patients, $40.8 \%$ in the OG group, and $60.6 \%$ in the LG group (Fig. 1B). The 5 -year OS rates for OG and LG with respect to pathological stage were (1) stage I, $87.5 \%$ and $84.2 \%$, respectively ( $\mathrm{P}=0.753)$; (2) stage II, $55.0 \%$ and $77.3 \%$, respectively $(\mathrm{P}=0.034)$; and (3) stage III, $25.6 \%$ and $34.8 \%$, respectively $(\mathrm{P}=0.302)$ (Fig. 2).

Thirty-six patients (50.7\%) in the OG group and 32 patients (29.4\%) in the LG group had recurrence of disease. The OG and LG groups did not differ significantly in terms of site of recurrence, with the most common recurrence sites being the peritoneum (18.7\%), an intra-abdominal organ (17.3\%), and the liver (16.0\%) (Table 3).

\section{Prognostic factors of disease-free survival and overall survival}

In the univariate analysis for DFS, type of surgery (OG vs. LG), tumor invasion, lymph node metastasis, and TNM stage significantly influenced the DFS $(\mathrm{P}<0.05)$. Finally, after the adjustment of seven baseline variables (age, gender, type of surgery, postoperative morbidity, and TNM stage) with a Cox regression analysis, TNM stage was found to be only independent predictive factors for DFS (Table 4).

As with OS, the type of surgery, tumor invasion, lymph node metastasis, and TNM stage affected the OS significantly in the univariate analysis $(\mathrm{P}<0.05)$. However, after the seven baseline variables (the same as above) were adjusted, the multivariate analysis confirmed that cancer stage was independent prognostic factors
Table 3. Differences in site of recurrence between patients undergoing open gastrectomy and laparoscopic gastrectomy

\begin{tabular}{lcccc}
\hline Recurrence site & $\begin{array}{c}\text { Total } \\
\text { no. (\%) }\end{array}$ & $\begin{array}{c}\text { OG } \\
(\mathrm{n}=71)\end{array}$ & $\begin{array}{c}\text { LG } \\
(\mathrm{n}=109)\end{array}$ & P-value \\
\hline Peritoneal seeding & $14(18.7)$ & 8 & 6 & 0.162 \\
Gastric bed & $8(10.7)$ & 5 & 3 & 0.264 \\
Remnant stomach & $7(9.3)$ & 3 & 4 & 0.998 \\
Liver & $12(16.0)$ & 7 & 5 & 0.223 \\
Lung & $6(8.0)$ & 3 & 3 & 0.942 \\
Bone & $5(6.7)$ & 3 & 2 & 0.384 \\
Brain and meningeal & $2(2.7)$ & 1 & 1 & 0.988 \\
Intra-abdominal organ & $13(17.3)$ & 8 & 5 & 0.153 \\
Ovary & $4(5.3)$ & 2 & 2 & 0.934 \\
External abdominal organ & $3(4.0)$ & 0 & 3 & 0.283 \\
Trocar site, skin & $1(1.3)$ & 0 & 1 & 0.894 \\
\hline
\end{tabular}

$O G$, open gastrectomy; $L G$, laparoscopic gastrectomy.

for OS (Table 5). The type of surgery was not found to be predictive of either DFS or OS on multivariate analysis.

\section{DISCUSSION}

Currently, reports have consistently proved long-term oncologic outcomes for LG in the management of EGC $[1,17,18]$. In addition, Korean Laparoscopy Gastrointestinal Surgery Study (KLASS) group (a large-scale multicenter trial, NCT00452751) is currently studying this issue with outcomes expected in the near future [3]. Given the success of LG for EGC in the Far East, many institutions have begun to expand the indications for LG to include both node positive and locally advanced tumors $[5,9,10]$. However, the role of 


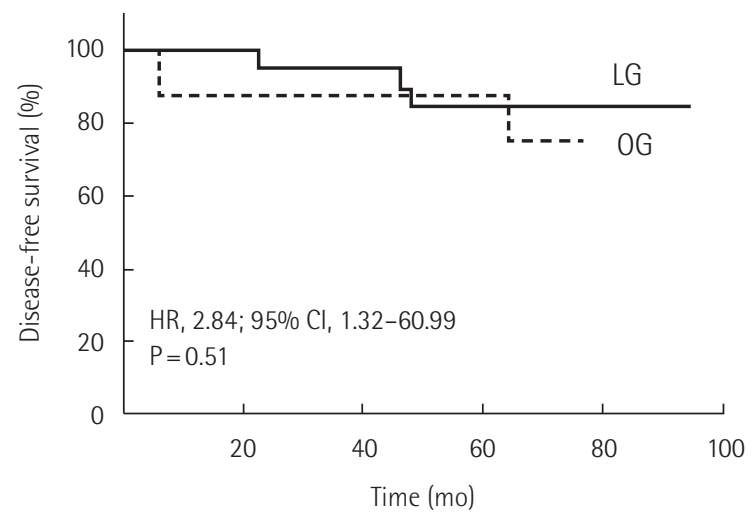

Stage I
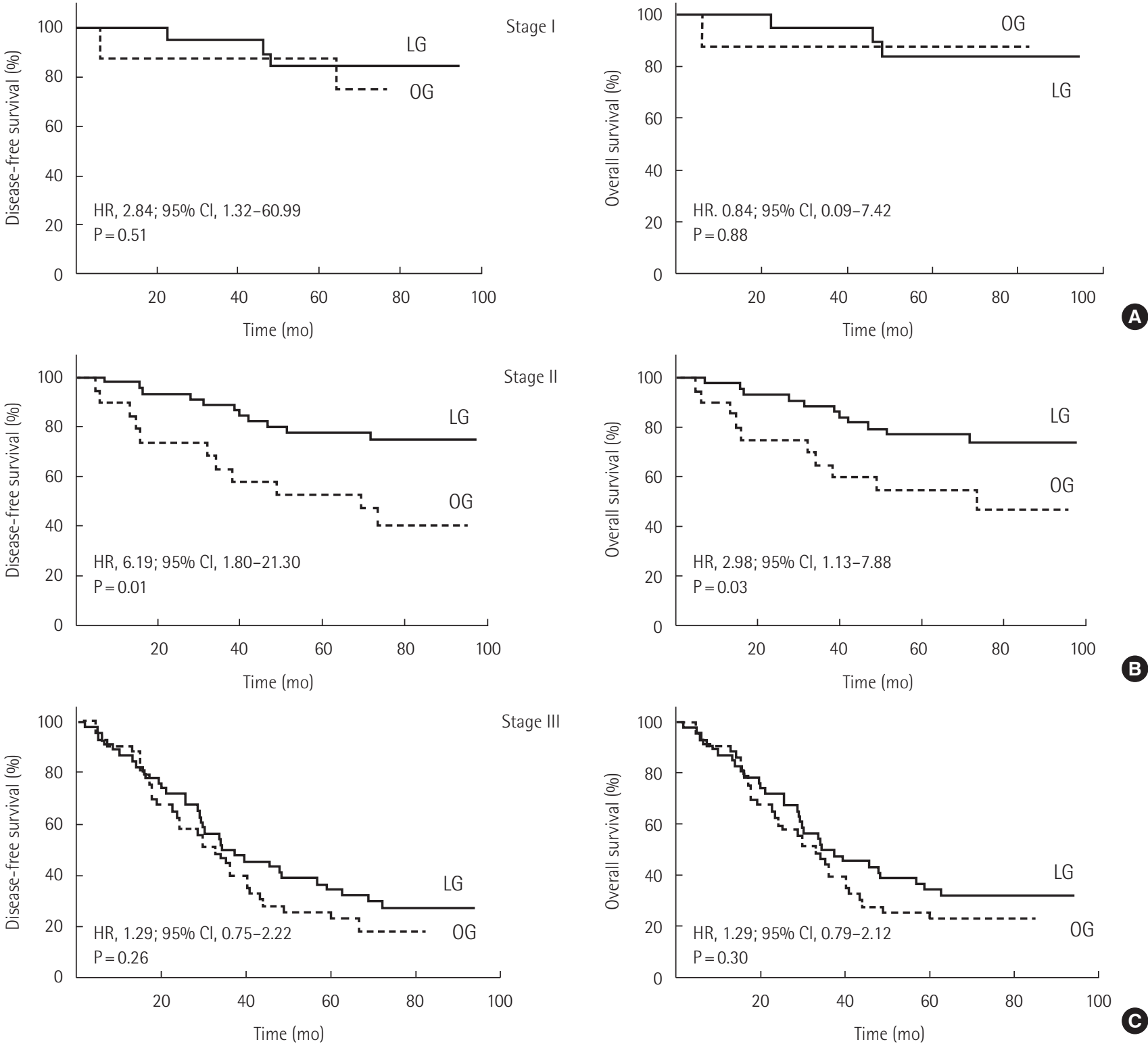

Fig. 2. Disease-free survival and overall survival according to stage: stage I (A), stage II (B), and stage III (C). LG, laparoscopic gastrectomy; $\mathrm{OG}$, open gastrectomy; $\mathrm{HR}$, hazard ratio; $\mathrm{Cl}$, confidence interval.

LG in AGC management remains controversial because of the limited study of long-term outcomes and technical difficulties. In the present study, we focused on long-term oncologic outcomes of patients with a sufficient follow-up period of at least 5 years. We found that LG with regional lymph node dissection had acceptable oncologic outcomes in terms of survival and recurrence compared with patients who underwent conventional OG.

Several reports have demonstrated the long-term outcomes of LG with D2 dissection as equivalent to the long-term outcomes of OG [5-10]. Shinohara et al. [5] demonstrated that the 5-year OS and DFS rates were $68.1 \%$ and $65.8 \%$, respectively, and there was no difference between LG and OG. The KLASS group [9] showed that the overall 5 -year survival rate of 239 AGC patients was $78.8 \%$, and the DFS rate was $85.6 \%$. They also described that the overall results stratified according to staging were comparable to historical data $[19,20]$. In the United States, MacLellan et al. [8] described that the 3-year relapse-free survival and OS rates were $58 \%$ and $65.9 \%$, respectively. In the present study, the 5 -year OS and DFS rates were all $60.6 \%$ in the LG group, which is an acceptable value when compared with previous reports. However, the outcomes of OG (5-year overall and DFS rates $40.8 \%$ and $39.4 \%$, respectively) were significantly poorer than the outcomes of $\mathrm{LG}(\mathrm{P}<0.01)$ (Fig. 
Table 4. Prognostic factors for disease-free survival for advanced gastric cancer

\begin{tabular}{|c|c|c|c|c|}
\hline \multirow{2}{*}{ Variable } & \multicolumn{2}{|c|}{ Univariate } & \multicolumn{2}{|c|}{ Multivariate } \\
\hline & $\mathrm{HR}(95 \% \mathrm{Cl})$ & P-value & $\mathrm{HR}(95 \% \mathrm{Cl})$ & P-value \\
\hline Age (yr) & & 0.384 & - & - \\
\hline$<65$ & 1.00 & & & \\
\hline$\geq 65$ & $1.33(0.71-2.49)$ & & & \\
\hline Sex & & 0.084 & - & - \\
\hline Male & 1.00 & & & \\
\hline Female & $0.55(0.28-1.08)$ & & & \\
\hline Type of surgery & & 0.008 & & 0.265 \\
\hline$O G$ & 1.00 & & 1.00 & \\
\hline LG & $0.42(0.23-0.78)$ & & $1.23(0.45-2.41)$ & \\
\hline Combined organ resection & & 0.673 & - & - \\
\hline No & 1.00 & & & \\
\hline Yes & $1.27(0.56-2.85)$ & & & \\
\hline Postoperative morbidity & & 0.198 & - & - \\
\hline No & 1.00 & & & \\
\hline Yes & $1.77(0.74-4.20)$ & & & \\
\hline Chemotherapy & & 0.546 & - & - \\
\hline No & 1.08 (0.59-1.98) & & & \\
\hline Yes & 1.00 & & & \\
\hline Tumor invasion (2 groups) & & 0.006 & - & - \\
\hline $\mathrm{T} 2 / \mathrm{T} 3$ & 1.00 & & & \\
\hline $\mathrm{T} 4$ & $2.29(1.28-4.11)$ & & & \\
\hline Lymph node metastasis (2 groups) & & 0.003 & - & - \\
\hline No/N1 & 1.00 & & & \\
\hline N2/N3 & $7.46(3.74-14.84)$ & & & \\
\hline TNM stage (2 groups) & & 0.001 & & 0.032 \\
\hline$|/| \mid$ & 1.00 & & 1.00 & \\
\hline III & $7.59(3.71-15.58)$ & & $2.79(0.93-3.89)$ & \\
\hline
\end{tabular}

$H R$, hazard ratio; $\mathrm{Cl}$, confidence interval; $\mathrm{OG}$, open gastrectomy; LG, laparoscopic gastrectomy; TNM, tumor node metastasis.

1). This difference may be related to discrepancy between $L G$ and OG group. OG group patients had higher TNM stage $(\mathrm{P}=0.028)$, more combined organ resection $(\mathrm{P}=0.002)$ rate and higher operative risk (marginally different co-morbidities and ASA score) than LG group those. Moreover, we tended to choose OG for patients with a high morbid risk to reduce the increased risk of anesthesia with the longer duration of LG surgery.

In the subgroup analysis for survival according to stage, we did not identify differences in survival rates between LG and OG at TNM stage I and III. However, the OS and DFS rates of stage II patients were significantly poorer in the OG group (Fig. 2). This worse outcome may be related to the nature of the OG group at TNM stage II, which included older patients (mean age, 69.3 years vs. 59.3 years), a higher co-morbidity rate ( $75 \%$ vs. $43.2 \%$ ), a higher postoperative complication rate (50\% vs. $27.3 \%$ ), a higher combined organ resection rate ( $45 \%$ vs. $25.5 \%$ ), and a low adjuvant chemo- therapy rate (60\% vs. $86.4 \%)$.

This study demonstrated that the type of surgery (LG vs. OG) and TNM stage were prognostic factors for OS and DFS after LG for AGC. However, multivariate analysis revealed that TNM stage was independent prognostic factors for survival. Two studies have analyzed the prognostic factors for survival in AGC patients $[8,9]$. Age, T stage, N stage, and overall stage were independent prognostic factors for survival. Eom et al. [21] reported that Lauren classification in addition to age and node metastasis were significant prognostic factors for survival in patients who underwent laparoscopic total gastrectomy.

Adequate lymph node dissection is vital when performing standard surgery for AGC. The need for adequate lymphadenectomy in advanced cancer has been established in the literature, although the extent remains a topic of debate [22,23]. About 50\% lymph node positivity was encountered in T2 gastric cancer and $83 \%$ lymph 
Table 5. Prognostic factors for overall survival for advanced gastric cancer

\begin{tabular}{|c|c|c|c|c|}
\hline \multirow{2}{*}{ Variable } & \multicolumn{2}{|c|}{ Univariate } & \multicolumn{2}{|c|}{ Multivariate } \\
\hline & $\mathrm{HR}(95 \% \mathrm{Cl})$ & P-value & $\mathrm{HR}(95 \% \mathrm{Cl})$ & P-value \\
\hline Age (yr) & & 0.864 & - & - \\
\hline$<65$ & 1.00 & & & \\
\hline$\geq 65$ & $1.11(0.73-1.69)$ & & & \\
\hline Sex & & 0.144 & - & - \\
\hline Male & 1.00 & & & \\
\hline Female & $0.71(0.45-1.12)$ & & & \\
\hline Type of surgery & & 0.010 & & 0.456 \\
\hline OG & 1.00 & & 1.00 & \\
\hline LG & $0.54(0.35-0.81)$ & & $1.23(0.55-3.24)$ & \\
\hline Combined organ resection & & 0.546 & - & - \\
\hline No & 1.00 & & & \\
\hline Yes & $1.02(0.63-1.67)$ & & & \\
\hline Postoperative morbidity & & 0.142 & - & - \\
\hline No & 1.00 & & & \\
\hline Yes & $1.53(0.87-2.72)$ & & & \\
\hline Chemotherapy & & 0.762 & - & - \\
\hline No & $1.08(0.59-1.98)$ & & & \\
\hline Yes & 1.00 & & & \\
\hline Tumor invasion (2 groups) & & 0.012 & - & - \\
\hline $\mathrm{T} 2 / \mathrm{T} 3$ & 1.00 & & & \\
\hline T4 & $1.86(1.16-3.06)$ & & & \\
\hline Lymph node metastasis (2 groups) & & 0.007 & - & - \\
\hline No/N1 & 1.00 & & & \\
\hline N2/N3 & $3.93(2.49-6.20)$ & & & \\
\hline TNM stage (2 groups) & & 0.001 & & 0.012 \\
\hline$|/| \mid$ & 1.00 & & 1.00 & \\
\hline III & $3.95(2.48-6.30)$ & & $3.21(0.65-5.87)$ & \\
\hline
\end{tabular}

$H R$, hazard ratio; $\mathrm{Cl}$, confidence interval; $\mathrm{OG}$, open gastrectomy; $L G$, laparoscopic gastrectomy; TNM, tumor node metastasis.

node metastasis in T3 cancer [24,25]. In addition, lymph node metastasis of AGC is frequently occurs in the suprapancreatic area (stations 7, 8a, 9, and 11p) [26]. Complete removal of this area is essential during radical surgery for AGC [27]. Our team carried out median lymph node retrieval of 28.5 in the LG group and 34.9 in OG group. This discrepancy may be attributed to selection bias, since patients with a high TNM stage were more likely to select open surgery rather than laparoscopy. In our institution, we performed more than D2 lymph node dissection in addition to basic D2 when N3 lymph node metastasis was detected by preoperative evaluation.

Despite the acceptable long-term outcomes, we failed to show a definite clinical advantage of LG over OG in terms of postoperative bowel recovery, hospital stay, and morbidity. This might be because in our study patients with LG or OG were managed under the same perioperative care practices in the early years of laparo- scopic surgery. Moreover, the long duration of LG (LG, 322.9 minutes; OG, 264.3 minutes) might contribute to these outcomes.

In our retrospective cohort study, the long-term results of LG for AGC were better than the long-term results of OG. However, in multivariate analysis for survival after adjustment for potential confounders, the type of surgical approach (LG vs. OG) did not influence the DFS and overall survival rates. TNM stage was only one independent prognostic factors for the long-term outcome.

This study had several limitations. Our data were limited by the retrospective nature of the data collection. When using retrospective data, direct comparisons of LG and OG seem methodologically inappropriate. Another limitation was the discrepancies between the LG and OG groups. Well-designed prospective randomized controlled trials are needed to corroborate our data and further verify the indications for LG for AGC.

The present study also had several advantages. Firstly, sufficient 
long-term follow-up could be used to evaluate survival. This study tracked patients for at least 5 years. Secondly, all interventions were performed by a single experienced laparoscopic surgeon. Thirdly, this report included patients undergoing surgery during a relatively short time period. Our study spanned 3-year period with a similar management policy for gastric cancer.

In conclusion, our analysis demonstrated that long-term oncologic outcomes at the 5-year follow-up after LG for AGC were acceptable compared with the long-term outcomes of OG. In addition, TNM stage was found to be significantly associated with sur vival on multivariate analysis.

\section{CONFLICT OF INTEREST}

No potential conflict of interest relevant to this article was reported.

\section{ACKNOWLEDGMENTS}

The authors would like to thank Jeong-Suk Suh and Young-Suk Kim, Research Nurse for conducting data collection and telephone interview.

\section{REFERENCES}

1. Kitano S, Shiraishi N, Uyama I, Sugihara K, Tanigawa N; Japanese Laparoscopic Surgery Study Group. A multicenter study on oncologic outcome of laparoscopic gastrectomy for early cancer in Japan. Ann Surg 2007;245:68-72.

2. Lee JH, Yom CK, Han HS. Comparison of long-term outcomes of laparoscopy-assisted and open distal gastrectomy for early gastric cancer. Surg Endosc 2009;23:1759-63.

3. Kim HH, Hyung WJ, Cho GS, Kim MC, Han SU, Kim W, et al. Morbidity and mortality of laparoscopic gastrectomy versus open gastrectomy for gastric cancer: an interim report-a phase III multicenter, prospective, randomized trial (KLASS trial). Ann Surg 2010; 251:417-20.

4. Kim HH, Ahn SH. The current status and future perspectives of laparoscopic surgery for gastric cancer. J Korean Surg Soc 2011;81: 151-62.

5. Shinohara T, Satoh S, Kanaya S, Ishida Y, Taniguchi K, Isogaki J, et al. Laparoscopic versus open D2 gastrectomy for advanced gastric cancer: a retrospective cohort study. Surg Endosc 2013;27:286-94.

6. Gordon AC, Kojima K, Inokuchi M, Kato K, Sugihara K. Longterm comparison of laparoscopy-assisted distal gastrectomy and open distal gastrectomy in advanced gastric cancer. Surg Endosc 2013;27:462-70.

7. Hamabe A, Omori T, Tanaka K, Nishida T. Comparison of long- term results between laparoscopy-assisted gastrectomy and open gastrectomy with D2 lymph node dissection for advanced gastric cancer. Surg Endosc 2012;26:1702-9.

8. MacLellan SJ, MacKay HJ, Ringash J, Jacks L, Kassam Z, Conrad T, et al. Laparoscopic gastrectomy for patients with advanced gastric cancer produces oncologic outcomes similar to those for open resection. Surg Endosc 2012;26:1813-21.

9. Park DJ, Han SU, Hyung WJ, Kim MC, Kim W, Ryu SY, et al. Longterm outcomes after laparoscopy-assisted gastrectomy for advanced gastric cancer: a large-scale multicenter retrospective study. Surg Endosc 2012;26:1548-53.

10. Zhao Y, Yu P, Hao Y, Qian F, Tang B, Shi Y, et al. Comparison of outcomes for laparoscopically assisted and open radical distal gastrectomy with lymphadenectomy for advanced gastric cancer. Surg Endosc 2011;25:2960-6.

11. Greene FL, Page DL, Fleming ID, Fritz A, Balch CM, Haller DG, et al. editors. American Joint Committee on Cancer (AJCC) cancer staging manual. 6th ed. New York, NY: Springer; 2002.

12. Japanese Gastric Cancer Association. Japanese classification of gastric carcinoma-2nd English edition. Gastric Cancer 1998;1:10-24.

13. Joo YT, Moon HG, Lee SH, Jeong CY, Jung EJ, Hong SC, et al. Laparoscopy-assisted distal gastrectomy with intracorporeal Billroth I stapled anastomosis using a hand access device for patients with gastric cancer. Surg Endosc 2007;21:859-62.

14. Kim SG, Lee YJ, Ha WS, Jung EJ, Ju YT, Jeong CY, et al. LATG with extracorporeal esophagojejunostomy: is this minimal invasive surgery for gastric cancer? J Laparoendosc Adv Surg Tech A 2008;18: 572-8.

15. Sano T, Yamamoto S, Sasako M; Japan Clinical Oncology Group Study LCOG 0110-MF. Randomized controlled trial to evaluate splenectomy in total gastrectomy for proximal gastric carcinoma: Japan clinical oncology group study JCOG 0110-MF. Jpn J Clin Oncol 2002;32:363-4.

16. Adachi Y, Katsuta T, Aramaki M, Morimoto A, Shiraishi N, Kitano S. Proximal gastrectomy and gastric tube reconstruction for early cancer of the gastric cardia. Dig Surg 1999;16:468-70.

17. Song J, Lee HJ, Cho GS, Han SU, Kim MC, Ryu SW, et al. Recurrence following laparoscopy-assisted gastrectomy for gastric cancer: a multicenter retrospective analysis of 1,417 patients. Ann Surg Oncol 2010;17:1777-86.

18. Kodera Y, Fujiwara M, Ohashi N, Nakayama G, Koike M, Morita S, et al. Laparoscopic surgery for gastric cancer: a collective review with meta-analysis of randomized trials. J Am Coll Surg 2010;211:67786.

19. Ahn HS, Lee HJ, Hahn S, Kim WH, Lee KU, Sano T, et al. Evaluation of the seventh American Joint Committee on Cancer/International Union Against Cancer Classification of gastric adenocarci- 
noma in comparison with the sixth classification. Cancer 2010;116: 5592-8.

20. Edge SB, Compton CC. The American Joint Committee on Cancer: the 7th edition of the AJCC cancer staging manual and the future of TNM. Ann Surg Oncol 2010;17:1471-4.

21. Eom BW, Kim YW, Lee SE, Ryu KW, Lee JH, Yoon HM, et al. Survival and surgical outcomes after laparoscopy-assisted total gastrectomy for gastric cancer: case-control study. Surg Endosc 2012;26: 3273-81.

22. Sasako M, Sano T, Yamamoto S, Kurokawa Y, Nashimoto A, Kurita A, et al. D2 lymphadenectomy alone or with para-aortic nodal dissection for gastric cancer. N Engl J Med 2008;359:453-62.

23. Songun I, Putter H, Kranenbarg EM, Sasako M, van de Velde CJ. Surgical treatment of gastric cancer: 15-year follow-up results of the randomized nationwide Dutch D1D2 trial. Lancet Oncol 2010; 11:439-49.

24. de Gara CJ, Hanson J, Hamilton S. A population-based study of tumor-node relationship, resection margins, and surgeon volume on gastric cancer survival. Am J Surg 2003;186:23-7.

25. Onate-Ocana LF, Aiello-Crocifoglio V, Mondragon-Sanchez R, Ruiz-Molina JM. Survival benefit of D2 lympadenectomy in patients with gastric adenocarcinoma. Ann Surg Oncol 2000;7:210-7.

26. Maruyama K, Gunven P, Okabayashi K, Sasako M, Kinoshita T. Lymph node metastases of gastric cancer: general pattern in 1931 patients. Ann Surg 1989;210:596-602.

27. Sasako M, McCulloch P, Kinoshita T, Maruyama K. New method to evaluate the therapeutic value of lymph node dissection for gastric cancer. Br J Surg 1995;82:346-51. 